\title{
Possible risks in construction of the facility in cramped conditions
}

\author{
Aleksandr Aleksanin* \\ Moscow State University of Civil Engineering, Yaroslavskoe shosse, 26, Moscow, 129337, Russia
}

\begin{abstract}
Today, we often have to deal with the implementation of works on the construction of buildings and structures in the central regions of large cities with already established buildings. This is especially true when implementing projects for renovation or reconstruction of historical objects. The article analyzes the main types of restrictions for construction in cramped conditions. For example, heavy traffic and pedestrians, the presence of underground utilities, the lack of sites for storing materials, difficult access to structures for their survey, the inability to use large construction equipment, etc. Cramped conditions create a whole range of restrictions for the construction works, which can lead to the emergence of a certain group of risks. The article discusses the main risk groups in construction (financial, temporary, project, quality) and their causes. In the article each of the restriction in the construction in cramped conditions and the risks that they can cause are analyzed.
\end{abstract}

\section{Introduction}

As a rule, the construction of new buildings in the central part of the city is associated with a shortage of vacant areas and is planned on-site facilities that are subject to dismantling and demolition. This is especially true in the implementation of renovation projects. At the location of obsolete production facilities, modern enterprises are being created or objects of a completely different status are being built. The change in the designation of industrial areas is caused by the inexpediency of keeping production enterprises within the city. In the housing stock renovation is often associated with the physical wear and tear of old objects that are not subject to reconstruction, on the site of which new residential houses of increased area and storeys are being erected [1-9].

In addition to new construction for the central part of the city, actual work is underway to reconstruct existing facilities, among which the greatest attention should be paid to buildings of historical value. It is obvious that the preservation of architectural monuments of the national heritage is an important task, however, modern practical needs of society often come into conflict with it. Currently, monuments are often rebuilt, adapt to the implementation of new functions, or completely eliminated and replaced by new structures. Instead of the demolished monument of architecture (in most cases stone or wooden), a "mock-up" is often constructed, which is only an external copy, an imitation of what was

\footnotetext{
* Corresponding author: aleks08007@ mail.ru
} 
built earlier. The range of construction works affecting the appearance of the building is very large: additional floors are being built, additional buildings are being erected, engineering support systems are being installed, and so on. The result is a new building, which is a sham copy of the original architectural monument [10-14].

The reasons, as a result of which it is necessary to carry out works on the reconstruction of buildings, can be divided into two groups: technogenic and socio-economic. The first group includes the effects of vibration, moisture, dust deposits, deterioration of structures and engineering communications, non-compliance with energy efficiency requirements. The second group includes the reasons for which there is a social need to use the building in a new functional purpose with internal reorganization. For example, the adaptation of buildings for offices, shopping centers, catering enterprises, etc.

\section{Theoretical Basis}

During the construction and reconstruction of buildings in the central part of the city, it is necessary to take into account the features of the existing building, which can make work more difficult. Constrained conditions create a whole set of restrictions for the production of construction and assembly works (Fig. 1), which can lead to the emergence of a certain group of risks. Risk - this is the probability of appearance in connection with a certain action or inaction of unsatisfactory values of the main indicators due to the deviation of the current situation from the planned one [15-19].

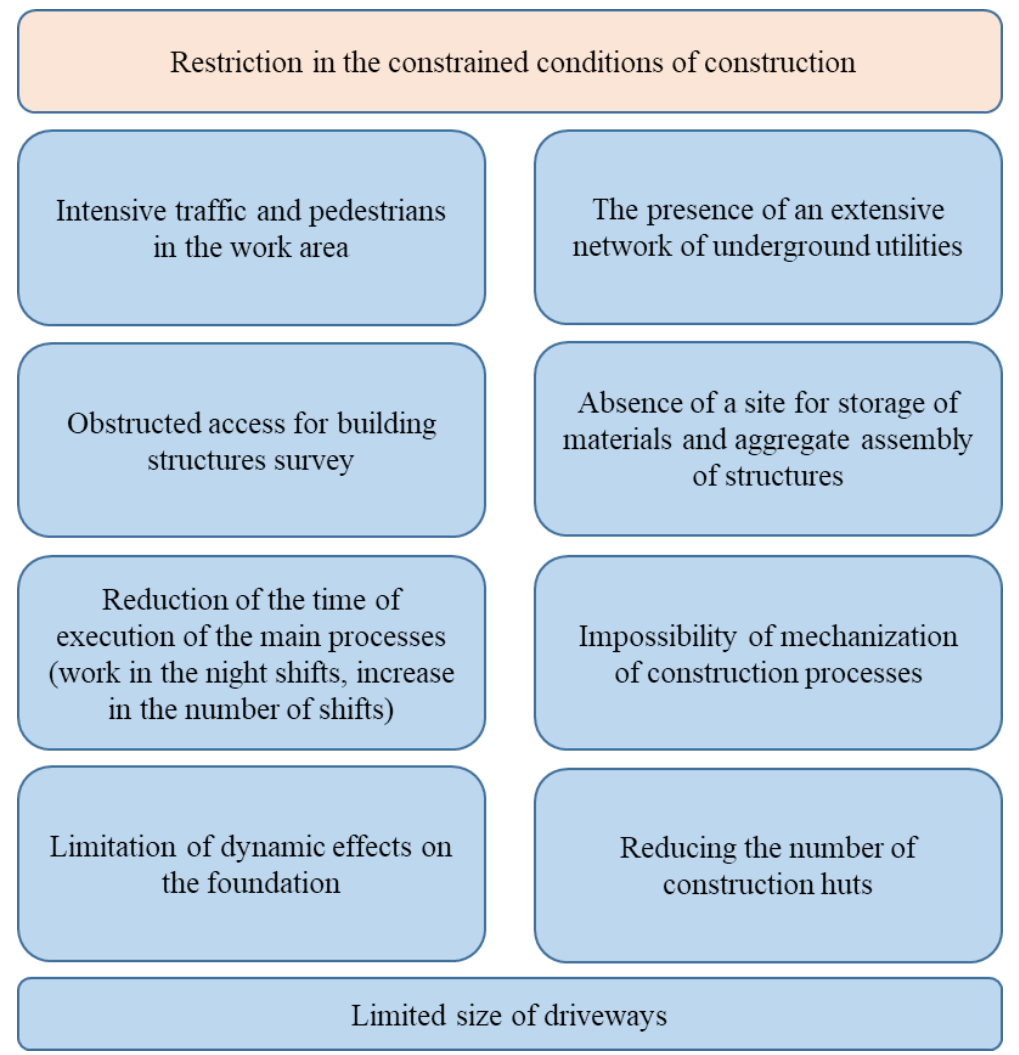

Fig. 1. Types of restrictions in construction in crowded conditions. 
The main types of risks in construction:

- financial - the cost of the project;

- temporary - construction time;

- project - providing the object with the purposes for which it was built;

- quality - the quality of materials and technology of work execution.

Distinguish the following reasons for the emergence of risks during construction:

- natural - losses from natural disasters;

- political - losses as a result of changes in state legislation, forms of power, public unrest;

- production - losses in the form of improper quality of materials, non-fulfillment of the calendar schedule of work.

- trading - a reduction in profits due to special conditions of contracts, delays in payment, as well as cash gaps;

- financial - losses due to inflation processes and volatility of the exchange rate.

To a separate group of reasons for the emergence of risks in the construction industry include cramped conditions. Let us consider in more detail the limitations in construction in cramped conditions and the risks to which they can lead.

\section{Results and Discussion}

Intensive traffic of vehicles and pedestrians next to the place of production leads to the need for temporary protective fences separating the zone of construction and installation works. The movement of traffic and pedestrians in the immediate vicinity of the place of work leads to the need to separate the facility into small organizational and technological modules, on which all work must be completed by a certain date. In the reconstruction sometimes it is necessary to protect the interiors of buildings and structures from external influences (debris, dust, exhaust, etc.). The restriction in question may lead to an increase in construction costs, that is, to financial risks.

The constrained conditions also lie in the limited area of the territory, the density of construction, the small radii of the curvature of roads. This leads to limited use of existing roads to transport materials and structures of great length. In connection with this, the transport scheme for the delivery of structures and the movement of construction equipment becomes more complicated, it becomes necessary to construct separate driveways to the site of construction or to expand existing ones. These works also increase the cost of construction and require additional time resources.

The lack of possibility to organize warehouse zones on the construction site complicates the material and technical support of the construction. Additional time resources are required for the movement of materials and structures within the site into the zone of action of the lifting mechanisms. It becomes necessary to organize transshipment warehouses outside the site. The stock of material resources must provide a common need for the entire amount of work. This can lead to additional risks in meeting construction deadlines, because outages due to logistical disruptions may result in downtime.

The risk of a decline in labor productivity during construction or reconstruction in cramped conditions is possible due to the impossibility of their mechanization. The limited use of construction equipment leads to an increase in the volumes of non-mechanized works. Enlarging assembly of building structures and technological equipment will have to be performed outside the site of the construction site. There is an internal constraint of the freedom of movement of building structures in the space inside the object. The development of the requirements and nomenclature of structures, products, materials, as well as the sequence of installation of the equipment to be installed becomes more complicated. The application of small-scale, multi-types, weighted mounted structures is 
increasing, there is a need for selective replacement of structures. This type of restriction can lead to the risk of quality loss of finished products. In addition, the increase in the labor intensity of work leads to additional costs associated with the introduction of new measures to ensure security and improve the working conditions of builders.

Restriction of the territory does not allow creating sites for enlargement of building structures and technological equipment, which limits the possibility of using large-block installation. Individuality of space-planning and constructive solutions leads to an increase in the use of building materials and a decrease in the degree of collection, does not allow the use of standard technological maps and industrial methods of production. As a result, project risks arise, related to the need to develop individual organizational and technological documentation.

Temporary risks include the possibility of performing certain construction works only at a certain time in connection with external constraints. For example, obtaining permission to block roads and sidewalks, which is issued only for certain hours during the day. Very often the allowed time for the reconstruction or construction of the facility falls on unfavorable periods. For example, construction and installation work is allowed only at night shifts, on weekends, etc. This type of restriction leads to an increase in the execution time of construction processes, low productivity of machines and mechanisms, additional expenses for their leasing in connection with the extension of the terms of stay at the construction site.

The risk of loss of quality of the work performed is related to the impossibility of a detailed survey of the facility. In cramped conditions, it is not always possible to gain access to all elements of the building structure in the event of its reconstruction. In this regard, there is a risk of additional costs for unforeseen work. For example, an increase in the scope of work to strengthen the structure, the need to adjust the project due to information obtained already in the process of performing the work.

The risk of loss of time and additional costs appears in the production of excavation in the presence of a branched network of existing underground utilities. It is possible to produce additional works on suspension or re-laying of communications, determining the order of their disconnection and the sequence of dismantling. It is possible to transfer networks located in the working area of objects under construction or reconstructed, the construction of temporary engineering communications. The laying of temporary communications can be carried out both in new trenches and on supports. The presence of a large number of engineering communications, limited use of construction equipment lead to an increase in the amount of manual labor.

In the work on concrete concreting the limitations of the construction site and the inability to travel the transport that delivers the concrete mixture are temporary risks, since the movement of concrete to the place of installation will be carried out inefficiently by a considerable amount of time.

\section{Conclusions}

Thus, when carrying out work in conditions of constrained urban development, it is necessary to take into account possible risks associated with limiting factors. There are two main methods of risk assessment. The method of expert assessments, which includes the process of collecting and summarizing the experts' opinion on the likely changes in the volumes and the necessary labor costs. And the statistical method, which is based on the application of indicators of completed analogs.

Before the production of works on the construction or reconstruction of facilities, it is necessary to assess the degree of influence of each of the risks listed in the article and develop measures to reduce and prevent them. That is, it is necessary to create a risk 
management system within the framework of the project. A realistic valuation of the value of the object should take an important role even at the design stage, which will save the actual cost of the project within reasonable limits in comparison with the calculated one.

\section{References}

1. V. Weiler, H. Harter, U. Eicker. Energy and Buildings. 134, 319 (2017)

2. A. Aleksanin. Industrial and Civil Engineering. 9, 77 (2017)

3. A. Aleksanin, S. Sborshikov. IOP Conf. Series: Materials Science and Engineering. 365, 062006 (2018)

4. B. Bobovec, R. Mandic, A. Pozojevic. Polytechnic and design. 4, 37 (2016)

5. Y. Zharov. Industrial and Civil Engineering. 5, 69 (2013)

6. Y. Zharov. Scientific review. 10-2, 242 (2015)

7. A. Subbotin, S. Sborshikov, N. Lazareva. Vestnik MGSU. 3, 247 (2014)

8. S. Sborshikov, N. Lazareva, Y. Zharov. Vestnik MGSU. 6, 165 (2014)

9. A. Aleksanin. IOP Conf. Series: Materials Science and Engineering. 365, 062011 (2018)

10. V. Ferretti, M. Bottero, G. Mondini. Journal of Cultural Heritage. 15, 644 (2014)

11. I. Aigwi, T. Egbelakin, J. Ingham. International journal of building pathology and adaptation. 36, 385 (2018)

12. C. Rodrigues, F. Freire. Journal of Cleaner Production. 157, 94 (2017)

13. A. Boeri, J. Gaspari, V. Gianfrate, D. Longo, C. Pussetti. Journal of Technology for Architecture and Environment. 12, 230 (2016)

14. A. Aleksanin. The Bulletin of BSTU named after V.G. Shukhov. 7, 28 (2017)

15. S. Sborshikov. Scientific review. 2, 183 (2009)

16. S. Renuka, C. Umarani, S. Kamal. Journal of Civil Engineering Research. 4, 31 (2014)

17. S. More, T. Hirlekar. International Research Journal of Engineering and Technology. 4, 2006 (2017)

18. K. Jayasudha, B. Vidivelli. Journal of Engineering and Applied Sciences. 11, 6943 (2016)

19. A. Aleksanin. Scientific review. 5, 12 (2017) 